on a full-time basis. When, as a result of progress as clinicians and helped by experience in research, candidates are considered suitable, they will be appointed to the specialist training grade of senior registrar. This grade can be entered only through open competition, but once entered should normally lead on to a consultant appointment. The amount of time spent in it or its equivalent on the university side varies, but is rarely less than four years, and can be longer.

During these four years, as well as when a registrar, rotations with other hospitals or other disciplines than general medicine are increasing in frequency. Rotation has a great value to the doctors under training, but the requirements of his research projects have nevertheless to be considered.

Probably in the future in the United Kingdom the point when a man's training is completed will be marked by some form of registration, certification, or accreditation. Nevertheless, this will not involve him in the passing of any examination such as the specialty boards in the United States of America, and the point where he is considered to be fully trained will, it seems likely, be determined by an examination of the content of his whole training and his reactions to it.

\section{Higher Examinations}

In the United Kingdom it is usually necessary to pass a higher examination at one of the royal colleges, and also to obtain a higher university degree-that is a doctorate of medicine (M.D.). The qualifying examination is for a bachelorship in medicine and surgery. These higher examinations are taken at variable times, but usually two, three, or four years after qualification, and it is unusual for anyone to enter the specialist training grade of senior registrar, or academic equivalent, unless he has obtained one or more postgraduate qualifications. An appointment as a consultant in the National Health Service, or to a permanent place in the university hierarchy, depends on successful competition for that post, and thus is separate from, but should follow soon upon, the conclusion of specialist training in general medicine. This training will have taken six, seven, or even eight years after registration, and one year longer after qualification.

St. Thomas's Hospital, London S.E.1

SIR JOHN RICHARDSON, Bart., M.v.o., M.D., F.R.C.P., Consultant Physician

\section{Sweden}

\section{GUNNAR BIÖRCK}

This topic is difficult to discuss at present, since the whole organization of medical education and training in Sweden is in a turmoil. In the last few years our Parliament has passed a series of Bills dealing with the following: general university reform; reform of the undergraduate medical curriculum; reform of postgraduate education and specialist recognition in medicine; and reform of research work for a thesis and a doctor's degrees in higher education as a whole-and therefore also in medicine. In addition, new laws have been passed about the staff structure

Seraphimer Hospital and Karolinska Institute, Stockholm, Sweden GUNNAR BIÖRCK, M.D., F.R.C.P., Head of the Department of Medicine and Professor of Medicine within hospitals, to make it easier to create two new features. Firstly, larger clinical departments in the main subjects (and at the same time allowing for interdepartmental subspecialization). Secondly, so-called "blocks" of related specialties, which extend outside individual hospitals to include activities and all types of doctor in a certain area and allow exchanges between the centre and periphery.

All of this legislation has been the result of different political and technical proposals and very little integration, if any, has occurred so far. The cumbersome job of making sense of the decisions in real life now rests with the Board of Health, the local authorities responsible for medical care, and the medical professor himself. It goes without saying that the medical faculties have the keys to the future, for it is only through them that reforms can materialize and-I would add-spiritualize. No specialty will be subjected to greater demands and pressure than internal medicine, the core of medicine-at-large. Not only will we have to assume responsibility for our own vast territory, but also to act as a cohesive force counteracting the disintegration from medicine at large of several otherwise freewheeling specialties, including general practice.

This is the background. We know what we have, or have had. We have the blueprints of the future. They are yet to be tested against reality. Parliament has voted principles, which is easy. It has not voted the necessary financial resources, and in a country which already has the highest taxes in the world money is increasingly difficult to extract from governments acting on behalf of taxpayers.

\section{Specialist Recognition}

Up to ten years ago specialist recognition in our country was a function of our own professional organization, the Swedish Medical Association-which had devoted much energy to raising professional standards. Late in the 1950's a committee of the Association suggested that the standards of the requirements for specialist recognition should be raised, and that special courses and formal examinations should be included. Nevertheless, the Government rejected this proposal aside and was prepared, if anything, to lower the standards to create more "specialists" and break the alleged monopoly of those who were.

Fortunately, our Scandinavian neighbours saved us from this fate by intimating that if it was put into practice Swedish specialists would no longer be accepted in their countries. Reluctantly, the government agreed to conform to a Scandinavian pattern, but only on the condition that the undergraduate curriculum was shortened accordingly. Thus the price of an improved postgraduate education was an impairment of the undergraduate one. This has been accomplished in two ways: firstly, by increasing the number of students admitted without providing corresponding resources, particularly as regards teachers; secondly, by shortening the period of studies, thereby gradually turning away from the former, liberal apprenticeoriented teaching to a more continental, crowded, formal teaching of assembly-line type, ending in a series of multiplechoice computerized examinations.

\section{New Curriculum}

Whereas formerly our students had five or six months of straight internal medicine in their fourth year and another round of four months, followed by an examination, before graduation during their seventh year, they will now be given only five months and a multiple-choice test in the middle of their fourth year-and that's that. Nevertheless, after graduation our future young doctors will have to serve a kind of rotating internship for 21 months, including six months in general practice, mainly as district health officers (neither future pathologists nor radiologists are particularly keen on this ordeal). 
After that, specialist training may follow for those who do not want to become general practitioners. This period lasts between four and five and a half years, depending on the specialty. For "general internal medicine" four years of medicine and six months of psychiatry is required; in most of the subspecialties within internal medicine (endrocrinology, cardiology, chest diseases, gastroenterology, nephrology, rheumatology, and care of the chronic sick) the rule is two years of general internal medicine, two years in the subspecialty, and six months in psychiatry. However, instead of psychiatry, doctors specializing in chest diseases will do radiology, gastroenterologists surgery, nephrologists urology, and rheumatologists orthopaedic surgery. During the four years the prospective specialists will have to pass six postgraduate courses (each lasting a week). Specialist recognition is now made by the Board of Health and Welfare.

Continuing education of the specialist takes place through annual week-long courses at one of our university hospitals (in rotation). These courses are administered by the Swedish Society for Internal Medicine and participation is voluntary. It is also planned to expand the annual scientific meeting of the Swedish Medical Society to satisfy the needs also of interdisciplinary exchange and collaboration by a series of symposia and panels with contributions from basic science, clinical and laboratory medicine, and social medicine.

\section{How Will the Blueprint Work?}

As I have repeatedly stressed, this is the blueprint. How it will work nobody knows as yet, and the new specialists will not be seen in action until after 1975. So until then our patients will have to live with the oldfashioned ones-if they can find one. For one of the features in my country over the years has been the emphasis-from customers, authorities, and the profession itself-on hospitals and hospitalization, and for almost two decades during and after the war all the newly qualified doctors went into the hospitals, and remained there. This facilitated the rapid expansion of hospital resources, but left a vacuum, increasingly difficult to fill, as older specialists working outside the hospital walls retired or died.

At present it seems unlikely that many single-handed specialists in internal medicine will put up their shingles in Sweden. Instead they will be found in group practices, with other specialists, working either in the public service or perhaps in the big cities and the suburbs in private co-operatives. There is an obvious tendency for the local public health authorities to attach a sort of consultant service to middle-sized hospitals for the care of the chronic sick, so that these consultants will have the laboratory and administrative machinery of the hospital at their disposal. Today internal medicine, care of the chronic sick, and geriatrics are closely interwoven; even in a university hospital such as the Seraphimer hospital in Stockholm the average age of the in-patients was recently found to be 62 years.

\section{Two Ubiquitous Problems}

I would like to end by expressing my concern over two problems, to which I feel we are exposed in my country-and I am afraid they are ubiquitous. The first is the problem of tailoring medical education and training so as to fit "the demands of the public"-which to a great extent means routine treatment of a limited number of common diseases-and at the same time to retain our traditional emphasis on medicine as an art of analytical thinking and scientific curiosity. The second is the challenge facing internal medicine at large from its own subspecialties. The attraction of the limited field, cultivated in depth, as against a vast realm, difficult and heartbreaking to govern and hold, is all too obvious among intellectuals. Rarely does a medical prince or duke strive for the imperial crown.
On the contrary, many of our best men decline the offer of such a crown, or give it happily away after having felt its weight. There is an apparent and appalling threat that internal medicine may disintegrate, not through any assault from the outsidewhich has repeatedly confessed that it needs it-but by withdrawal from responsibility within our own body of peers.

To carry the ultimate responsibility for internal medicine today-which does not mean any pretence that one knows the subtle details of the various subspecialties-is a hard task. We must, in due time-that is, always-find and educate young men and women with the proper stamina, who are willing and prepared when necessary to accept the challenge of the stern unity and the sacrifice of a beloved part.

\section{Belgium and Luxembourg}

\section{R. DE MEUTTER, R. SCHAUS}

In Belgium, as opposed to other countries, the term "internal medicine" and "specialist in internal medicine" came into usage as late as around 1935. Nevertheless, we had to wait until 1946 before our Society of Internal Medicine was created and until 1955 before the Professional Union of Specialists in Internal Medicine was created. Finally, in a ministerial decree published in 1957 relating to sickness insurance, internal medicine was established as a specialty among others such as cardiology, gastroenterology, neurology, and chest diseases.

There is no official diploma in internal medicine in Belgium. Some universities, after a candidate has taken special postgraduate studies and a final examination, give a certificate of internal medicine; nevertheless, whatever the quality of this certificate, it has no legal value. Internal medicine has been designated officially only within the framework of approval of specialists for the diagnosis and treatment of patients under our national sickness insurance scheme, which covers the vast majority of the population. This designation is done by the minister of public health, based on lists of internal medicine specialists submitted to him by the Bureau of the Professional Union of Physicians. There are two "Commissions of Approval" one French-speaking the other Flemish-speaking, as well as two appeal commissions.

\section{Specifications of Course}

In 1958 a supplementary ministerial decree laid down that to be registered as a specialist in internal medicine a doctor must have served several full-time "stages" for five years (or halftime stages of 10 years) in a university department of internal medicine or any "equivalent" department of internal medicine. This concept of "equivalence" was quite vague and in some cases led to difficulties over assessment. Hence in 1970 and 1971 the two commissions of approval (the French- and Flemish-speaking) laid down specifications not only for the criteria but also for the departments in which the stages took place. Training still lasts five years full time; at least three years of these have to be devoted to the clinical practice of general internal medicine in one or several university departments. This system of stages allows two of the years to be spent in non-university departments of internal medicine, or eventually in related fields such as morbid anatomy, radiology, cardiology, or medical biology. It was also recommended that

\section{University of Brussels and Renaix Hospital, Brussels, Belgium}

R. DE MEUTTER, M.D., Consultant in Internal Medicine and Tutor in Medicine

Institute of the Grand Duchy of Luxembourg

R. SCHAUS, M.D., President of the Faculty of Medical Sciences 